\title{
Statistical modeling of number of human deaths per road traffic accident in Oromia region, Ethiopia
}

\section{CURRENT STATUS: UNDER REVIEW}

BMC Public Health $\triangle$ BMC Series

Merga Abdissa Aga

Salale University

mergabdisa3@gmail.comCorresponding Author

ORCiD: https://orcid.org/0000-0003-4291-6247

Berhanu Teshome Woldeamanuel

Salale University

Mekonnen Tadesse

Addis Ababa University

\section{DOI:}

10.21203/rs.3.rs-19202/v1

\section{SUBJECT AREAS}

Health Economics \& Outcomes Research Health Policy

\section{KEYWORDS}

Count Regression models, Hurdle Poisson Model, number of human deaths per accident, Oromia regional state, Ethiopia 
Abstract

Abstract

Background : Globally, road traffic accidents are leading causes of death among young people in general, and the main cause of death among young people aged 15-29 years. This study was conducted to identify the major factors associated with the number of human deaths by road traffic accident in the Oromia Regional State, Ethiopia. Methods: We used data obtained from the Oromia Police Commission Bureau that have been recorded on daily basis road traffic accidents from July, 2016 - July, 2017. Count regression models were was used to assess the factors associated with the number of human deaths from traffic accidents. Results : Of the total of 3900 road traffic accidents included in the 1188 (30.5\%) were giving rise to fatal. The Hurde models were of better fit than zero inflated Poisson and zero inflated negative binomial model. Thus, the Hurdle Poisson is recommended in this study. Age of the driver $31-50$ years (AOR $=0.289,95 \% \mathrm{Cl}: 0.175,0.479)$ and higher than 50 years of age $(A O R=0.311,95 \% C l: 0.129,0.751)$, driver's years of experience $5-10$ years $(A O R=$ $0.014,95 \% \mathrm{Cl}: 0.007,0.027)$, and more than 10 years $(\mathrm{AOR}=0.101,95 \% \mathrm{Cl}: 0.057,0.176)$, vehicle type automobile $(A O R=8.642,95 \% \mathrm{Cl}: 2.7644,27.023)$, vehicle years of service $5-10$ years $(A O R=$ $2.484,95 \% \mathrm{Cl}: 1.194,5.169)$, and more than 10 years ( $\mathrm{AOR}=2.639,95 \% \mathrm{Cl}: 1.268,5.497$ ), type of accident, vehicle upside down ( $A O R=5.560,95 \% \mathrm{Cl}: 2.506,12.336)$, causes of accident, turning illegal position $(A O R=0.454,95 \% \mathrm{Cl}: 0.226,0.913)$, area of accident, residential place $(A O R=$ 108.506, 95\%Cl: 13.725, 857.798), working areas ( $\mathrm{AOR}=129.606,95 \% \mathrm{Cl}: 16.448,1021.263)$, near hospitals $(A O R=23.789,95 \% \mathrm{Cl}: 3.038,186.298)$, geographical locations, Western zones $(\mathrm{AOR}=$ $0.275,95 \% \mathrm{Cl}: 0.167,0.455)$, and South east zones (AOR $=0.624,95 \% \mathrm{Cl}: 0.410,0.950)$ were significant associated number of human deaths per road traffic accident factors in the study area. Conclusion : In this study, $30.5 \%$ of accidents were giving rise to at least one human death per road traffic accident and different associated numbers of human deaths per traffic accident factors have been identified.

Full Text

Due to technical limitations, full-text HTML conversion of this manuscript could not be completed. 
However, the manuscript can be downloaded and accessed as a PDF.

Figures

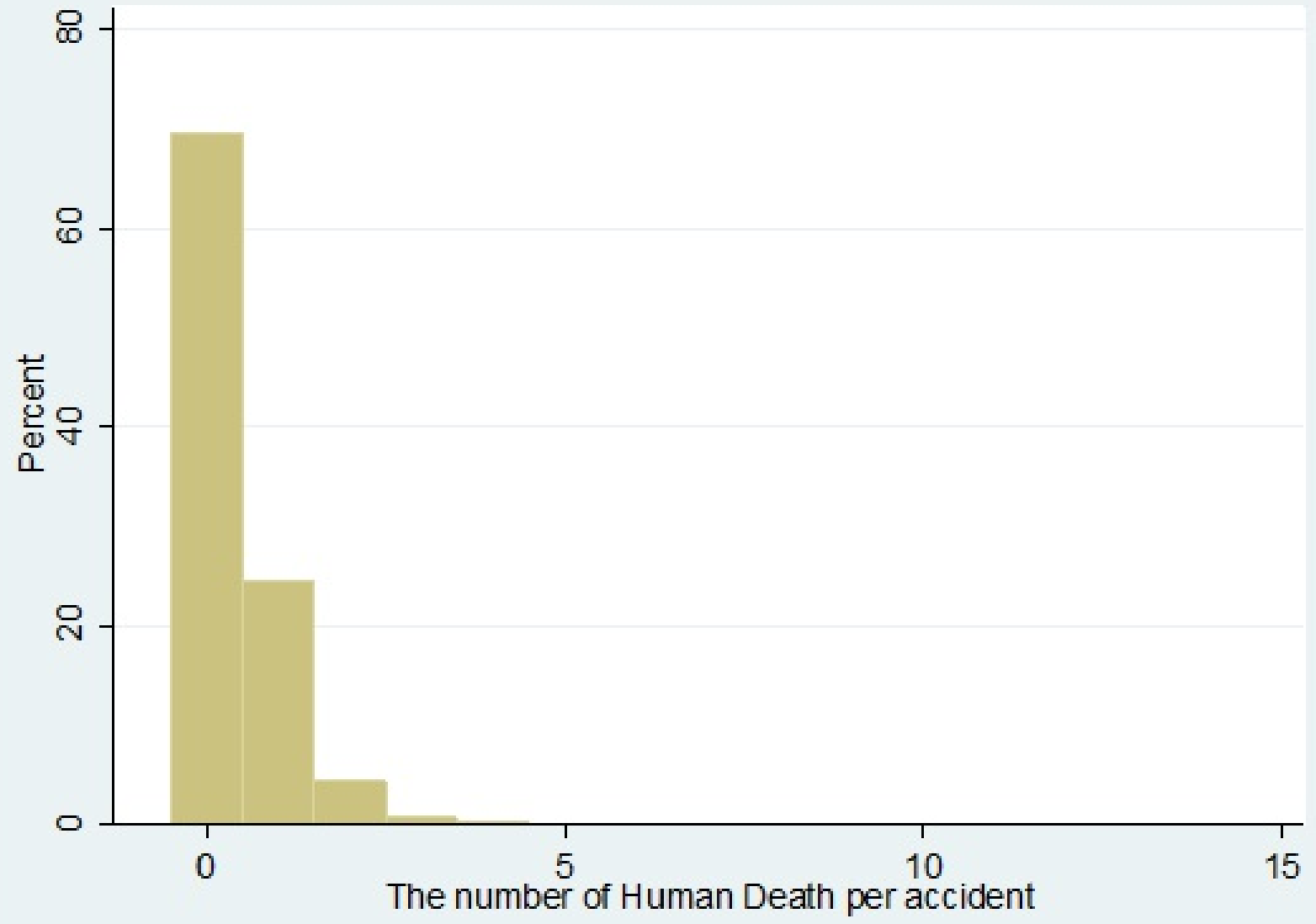

Figure 1

Distribution of response variable, count of human death per accident 